\title{
ESTIMATIVA DO POTENCIAL DE PRODUÇÃO DE BIOGÁS E ENERGIA NA INDÚSTRIA DE ABATE DE FRANGOS NO BRASIL ${ }^{1}$
}

\author{
Michelle Malaggi ${ }^{2}$, Samuel Nelson Melegari de Souza ${ }^{3}$ \\ ${ }^{1}$ Aceito para publicação no $3^{\circ}$ trimestre de 2014 \\ ${ }^{2}$ Universidade Estadual do Oeste do Paraná, Mestranda em Bioenergia \\ ${ }^{3}$ Universidade Estadual do Oeste do Paraná, Docente no Centro de Ciências Exatas e Tecnológicas \\ *malaggimichelle@gmail.com
}

\section{Resumo}

O presente trabalho teve como objetivo estimar a produção de biogás proveniente das indústrias brasileiras de abate de frangos e a sua capacidade de produzir energia por meio do biogás. Os dados base foram obtidos junto a uma agroindústria avícola que serviu como referência. A empresa possui um abate médio de 266 mil frangos por dia, com sistema de tratamento de efluentes baseado no biodigestor modelo canadense, o qual através da degradação anaeróbia produz o biogás como resultado final. A indústria de abate de frangos produz em média 743,77 $\mathrm{m}^{3} \cdot \mathrm{dia}^{-1}$ de biogás, ou seja, gera $2,78 \mathrm{~m}^{3} \cdot \mathrm{dia}^{-1}$ por animal abatido. Cuja conversão em eletricidade através de motores geradores é de 1,47 kWh. Com estes dados e outros obtidos em literaturas pertinentes, conseguiu-se estimar que o Brasil possui capacidade para gerar $39.335,44 \mathrm{mil} \mathrm{m}^{3}$.dia ${ }^{-1}$ de biogás e de produzir $57.823,11 \mathrm{kWh}$ de energia elétrica.

Palavra: Agroindústria avícola, Biodigestor, Biogás, Energia.

\section{POTENTIAL FOR BIOGAS PRODUCTION AND ENERGY IN POULTRY AGROINDUSTRY IN BRAZIL}

\begin{abstract}
The current paper had as an objective to calculate the amount of biogas being made by the Brazilian chicken slaughter companies and the biogas capacitance for producing energy. Some of the substantial data from this paper was gathered in partnership with a poultry agroindustry
\end{abstract}


that served as standard basis. The company has a daily cull of 266 thousands chickens a day, with a treatment system based on the Canadian bio digestive model, which through anaerobic digestion produces biogas as a result. The chicken slaughter industry produces an average of $743,77 \mathrm{~m}^{3}$.day ${ }^{-1}$ of biogas meaning that, it generates $2,78 \mathrm{~m}^{3}$.day ${ }^{-1}$ per slaughtered animal. Which its electricity production is of $1,47 \mathrm{kWh}$. With this data and other ones taken from relevant readings, we were able to calculate that Brazil has a capability of producing $39.335,44$ thousands $\mathrm{m}^{3}$.day ${ }^{-1}$ of biogas and generating $57.823,11 \mathrm{kWh}$ of electricity.

Keywords: Poultry agroindustry; Biodigester; Biogas; Energy.

\section{Introdução}

A energia tornou-se indispensável à sociedade, com uso nas mais variadas atividades, multiplicando a sua demanda a cada ano. Entretanto as formas de obtenção dessa energia vêm sofrendo alterações periódicas, onde antes eram obtidas quase que na sua totalidade das fontes não renováveis, como o petróleo e o carvão mineral, atualmente também é adquirida por meio de origem renovável, como a eólica, marémotriz, hidráulica e ainda a biomassa, oriunda de processos indústriais, urbanos ou agrícolas.

O uso das fontes alternativas de energia passou a ter um crescimento ininterrupto e, no mundo todo, programas e pesquisas começaram a ganhar espaço, mostrando a necessidade de se utilizar outros recursos geradores de eletricidade, como o aproveitamento da biomassa residual oriundas de atividades industriais.

No cenário agroindustrial brasileiro, a cadeia produtiva de carnes de suínos e aves destacam-se devido a grande quantidade de resíduos líquidos gerados nos processos de abate e industrialização de carnes. Estes resíduos são conhecidos como biomássicos e possuem grande capacidade de aproveitamento energético.

Para que seja possível a correta aplicação destes resíduos faz-se necessário o uso de tecnologias como o emprego de biodigestores, através do modelo canadense, o mais utilizado para resíduos agroindustriais, que proporcionam as condições adequadas para a digestão anaeróbia e que produz como resultado o biogás, com características físico-químicas que lhe conferem a capacidade de aproveitamento energético.

Diante do contexto apresentado, o presente estudo teve como objetivos estimar o potencial de biogás que poderia ser produzido pelas indústrias brasileiras de abate de frango e sua capacidade para gerar energia. 
Para atender o objetivo foi necessário o desenvolvimento das seguintes etapas: a caracterização da biomassa utilizada para gerar biogás numa indústria de abate de frangos; a obtenção das concentrações de sulfeto de hidrogênio no biogás e poder calorífico que informariam a qualidade do biogás e seu poder energético; a quantificação da média mensal de produção do biogás nos meses de janeiro a junho de 2012, bem como a produção de biogás por frango abatido, como base para os cálculos de estimativa, como referência para o estudo foi utilizada uma indústria de abate de frangos da região Oeste do Paraná.

\section{Material e métodos}

A metodologia desenvolvida para aplicar neste trabalho consistiu em buscar dados junto a uma indústria de abate frangos que possui sistema de produção de biogás e conversão em energia. A partir de dados coletados em fontes bibliográficas, como as informações do número de frangos abatidos no Brasil no ano de 2012, foi possível calcular a estimativa dos estados e das regiões brasileiras para produzir biogás e convertê-lo em energia.

\section{Sistema de Tratamento dos Efluentes da Indústria}

Características da biomassa como $\mathrm{pH}$, temperatura, tempo de retenção hidráulica do substrato, poder calorífico superior, demanda bioquímica e demanda química de oxigênio e a concentração de sólidos, possibilitaram estabelecer uma comparação com as literaturas pertinentes e avaliar a sua importância no processo de produção do biogás, bem como o bom desempenho do biodigestor e da digestão anaeróbia. Estes dados foram adquiridos junto a empresa que serviu de referencia para o desenvolvimento do estudo, a empresa forneceu apenas valores, não mencionando os métodos analíticos utilizados.

Biodigestores: O modelo de biodigestor utilizado na indústria de abate de frangos foi o canadense, com vazão máxima de $310 \mathrm{~m}^{3} \cdot \mathrm{h}^{-1}$, sendo que $186 \mathrm{~m}^{3} \cdot \mathrm{h}^{-1}$ é proveniente do biodigestor 01 e $124 \mathrm{~m}^{3} \cdot \mathrm{h}^{-1}$ do biodigestor 02 . A cobertura dos dois biodigestores é de geomembrana flexível de polietileno de alta densidade, fixada dentro de uma vala de $50 \mathrm{~cm}$ de largura por 50 $\mathrm{cm}$ de profundidade, recoberta com solo em todo o perímetro do biodigestor a uma distância de $60 \mathrm{~cm}$ da lagoa. A biomassa originada na indústria é disposta em uma caixa de passagem, introduzida nos biodigestores a 1,50 $\mathrm{m}$ do seu fundo.

O biodigestor 01 contém seis saídas de biogás e o biodigestor 02 possui quatro saídas, todas perfuradas na geomembrana com $50 \mathrm{~mm}$ de diâmetro e com tampão rosqueável, o qual permite a instalação de tubulação de captação de biogás. A tubulação que transporta o biogás 
da indústria de abate de frangos está projetada em 4 ramais, que saem do biodigestor 01 e 02 , com um ramal principal que leva o gás ao motor gerador de eletricidade e o gás ao flare.

Obtenção das Concentrações de $\mathrm{H}_{2} \mathrm{~S}$ do Biogás e Poder Calorífico

O sulfeto de hidrogênio produzido no biogás junto com metano e dióxido de carbono, foram obtidos junto à indústria de abate de frangos, por meio do aparelho analisador portátil de gases, marca/modelo: Dräger/Oda Logger. Foi possível estimar o poder calorífico do biogás por meio das concentrações de metano, permitindo estimar a sua capacidade teórica para gerar energia.

Estimativa da Produção de Biogás

Para a obtenção dos dados que proporcionaram o cálculo da produção média de biogás nos meses de janeiro a junho de 2012 foi utilizado medidor de dispersão mássica, marca Magnetrol.

\section{Quantidade de Biogás por Animal Abatido}

Para estimar a produção diária de biogás por animal abatido dos meses de janeiro a junho de 2012 utilizou-se a equação 1. Os valores médios de produção de biogás encontrados anteriormente foram divididos pelo número de animais abatidos diariamente.

$$
B A_{D}=\frac{P M}{F A}
$$

Onde $B A_{D}$ representa a quantidade de Biogás por animal por dia $\left(\mathrm{m}^{3}\right)$, PM produção média de biogás $\left(\mathrm{m}^{3}\right)$ e FA refere-se a frangos abatidos por ano.

\section{Potencial de Produção de Biogás na Indústria de Abate de Frangos no Brasil}

Por meio de pesquisa bibliográfica obteve-se a quantidade de frangos abatidos anualmente no Brasil, como observado na Tabela (1).

Tabela 1 - Abate anual de frangos por estado

\begin{tabular}{cc}
\hline Estado & Quantidade \\
\hline Paraná & 1.451 .274 .959 \\
Santa Catarina & 887.353 .445 \\
\hline
\end{tabular}




\begin{tabular}{cc}
\hline Rio Grande do Sul & 728.760 .296 \\
São Paulo & 684.115 .111 \\
Minas Gerais & 407.510 .025 \\
Goiás & 322.285 .423 \\
Mato Grosso & 239.518 .502 \\
Mato Grosso do Sul & 141.465 .086 \\
Bahia & 80.726 .470 \\
Pernambuco & 47.989 .818 \\
Pará & 41.788 .449 \\
Rio de Janeiro & 40.425 .962 \\
Espírito Santo & 26.313 .211 \\
Paraíba & 19.012 .539 \\
Distrito Federal & 20.956 .242 \\
Outros & 25.053 .460 \\
Total Anual & $\mathbf{5 . 1 6 4 . 5 4 8 . 9 9 8}$ \\
\hline
\end{tabular}

Fonte: Instituto Brasileiro de Geografia e Estatística (2012).

Por meio da equação (2) foi possível obter a quantidade de animais abatidos por dia.

$$
F A_{d}=\frac{F A_{a}}{365}
$$

Onde FAd são os frangos abatidos por dia.

A quantidade de frangos abatidos diariamente em cada estado brasileiro atrelado a média de produção de biogás por animal abatido, permitiu estimar o potencial de produção de biogás por meio da equação (3).

$$
F A_{d} \times P B A=\frac{P B T}{1000}
$$

Onde PBA é produção média de biogás por animal equivalente a $2,78 \mathrm{~m}^{3} \cdot \mathrm{dia}^{-1}$ e PBT é a Produção de biogás total por me em $\mathrm{m}^{3} \cdot \mathrm{dia}^{-1}$.

Os mesmos cálculos foram utilizados para estimar o potencial de produção de biogás nas regiões brasileiras. 


\section{Potencial de Produção de Energia Elétrica a partir do Biogás}

Para converter biogás em energia é necessário o uso de motores gerados com combustão interna. A indústria de abate de frangos tomada como base possui dois motores geradores operando conjuntamente com potência de $158 \mathrm{~kW}$ e um consumo médio de biogás de $108 \mathrm{~m}^{3} \cdot \mathrm{h}^{-}$ ${ }^{1}$, ou seja, chegando-se ao resultado de $1,47 \mathrm{kWh}$. Sabendo-se que $1 \mathrm{~m}^{3}$ de biogás equivale a $1,47 \mathrm{kWh}$, estimou-se a quantidade de energia que cada estado da federação e região poderia produzir em kWh através da equação (4).

$$
E=P B T \times 1,47
$$

Onde E é a energia produzida.

\section{Resultados e discussões}

\section{Caracterização da Biomassa}

A eficiência do biodigestor no processo de conversão da biomassa em biogás depende de alguns fatores biológicos, bem como das características físico-químicas da biomassa utilizada. A temperatura média na produção de biogás foi de $30,3{ }^{\circ} \mathrm{C}$, demonstrando ser apropriada para produção do gás. Segundo Nishimura (2009) a temperatura exerce influencia diretamente sobre o metabolismo das bactérias. $\mathrm{O}$ pH, outro parâmetro relevante, apresentou índice de 6,53, considerado ótimo para a atividade enzimática. Segundo Costa (2006), níveis de $\mathrm{pH}$ ácido deixam a atividade enzimática nula, já em meio alcalino, a fermentação produz anidrido sulforoso e hidrogênio.

O valor encontrado para os sólidos suspensos voláteis foi de $1.118 \mathrm{mg} . \mathrm{L}^{-1}$ e de sólidos totais foi de $2.798 \mathrm{mg} . \mathrm{L}^{-1}$. Segundo Lucas Junior (1994), quanto maior a quantidade de sólidos na alimentação constante dos biodigestores, maior será a capacidade de produzir biogás (LUCAS JUNIOR, 1994).

O Tempo de Retenção Hidráulica (TRH) é o tempo em que o substrato permanece no biodigestor para que seja digerido pelas bactérias anaeróbias (OLIVEIRA et al. 2005), na indústria de abate de frangos o TRH foi de 26 dias. O PCI do metano encontrado na indústria de abate de frangos foi de 7,6 kWh. Para Iannicelli (2008) o poder calorífico pode variar entre 4,95 a 7,92 kWh.

$\mathrm{A} \mathrm{DBO}_{5,20}$ média da biomassa foi de $2.345 \mathrm{mg} . \mathrm{L}^{-1}$, a DQO média de entrada foi de 5.088 mg.L. $\mathrm{L}^{-1}$, já da saída do biodigestor 1 foi de $1.640 \mathrm{mg} . \mathrm{L}^{-1}$ e do biodigestor 2 foi de $582 \mathrm{mg} . \mathrm{L}^{-1}$. 
Segundo Cortez, Lora e Gómez (2008), a estes valores estão ligados a quantidade de oxigênio necessária para estabilizar um composto orgânico por meio da ação de microrganismos em condições anaeróbias.

\section{Obtenção das Concentrações de $\mathrm{H}_{2} \mathrm{~S}$ no Biogás e Poder Calorífico}

A concentração média de sulfeto de hidrogênio no biogás na saída do biodigestor foi de $1.302,36$ ppm, o qual após passar pelo filtro com limalha de ferro, instalado antes do motor gerador, passa a ser de 843,88 ppm, com uma remoção média de 458,48 ppm.

A importância de remover o $\mathrm{H}_{2} \mathrm{~S}$ deve-se ao fato de ser um gás altamente tóxico e irritante que afeta o sistema nervoso, os olhos e as vias respiratórias (LINS et al. 2005). Outro aspecto relevante para a produção de biogás é o poder calorífico. A presença do metano e outros gases no biogás fazem com ele tenha um poder calorífico que varia de 856,06 a $8.132,78 \mathrm{kcal} / \mathrm{m}^{3}$ (IANNICELLI, 2008). Na industria esse valor esteve estimado em $6.564,08 \mathrm{kcal} / \mathrm{m}^{3}$ ou 7,6 $\mathrm{kWh}$.

\section{Estimativa da Produção de Biogás}

A média total de produção de biogás nos meses de janeiro a junho foi de $743,77 \mathrm{~m}^{3}$.dia ${ }^{1}$, sendo que janeiro apresentou o menor índice médio de produção de biogás, 642,86 $\mathrm{m}^{3}$.dia ${ }^{-1} \mathrm{e}$ abril a maior média de produção 787,99 $\mathrm{m}^{3} \cdot \mathrm{dia}^{-1}$, conforme Tabela 2.

Tabela 2 - Média de produção de biogás entre Janeiro e Junho de 2012

\begin{tabular}{ccc}
\hline Mês & $\begin{array}{c}\text { Produção de biogás médi } \\
\left(\mathbf{m}^{\mathbf{3}} \cdot \mathbf{d i a}^{\mathbf{- 1}}\right)\end{array}$ & Desvio Padrão \\
\hline Janeiro & 642,86 & 85,88 \\
Fevereiro & 726,51 & 120,76 \\
Março & 762,66 & 114 \\
Abril & 787,99 & 116,76 \\
Maio & 758,54 & 92,42 \\
Junho & 784,11 & 0 \\
Média & $\mathbf{7 4 3 , 7 7}$ & ---- \\
\hline
\end{tabular}

Quantidade de Biogás por Animal Abatido 
A correlação do número de animais abatidos por mês, a produção de biogás e a quantidade de biogás que cada animal gera estão apresentados na Tabela 3 .

Tabela 3 - Produção de Biogás por animal abatido numa Unidade Industrial de Aves

\begin{tabular}{|c|c|c|c|}
\hline \multirow[t]{2}{*}{ Mês } & \multirow{2}{*}{$\begin{array}{l}\text { Animais abatid } \\
\quad \text { aves.dia }^{-1} \text { ) }\end{array}$} & \multicolumn{2}{|c|}{ Produção média $1\left({ }^{-3}{ }^{-3}\right) \mathrm{m}^{3}$ de biogás.anil } \\
\hline & & biogás $\left(\mathrm{m}^{3} \cdot \mathrm{dia}^{-}\right.$ & ${ }^{1} . \operatorname{dia}^{-1}$ \\
\hline Janeiro & 250.000 & 642,86 & 2,57 \\
\hline Fevereiro & 265.000 & 726,51 & 2,74 \\
\hline Março & 268.000 & 762,66 & 2,84 \\
\hline Abril & 274.000 & 787,99 & 2,87 \\
\hline Maio & 270.000 & 758,54 & 2,80 \\
\hline Junho & 272.000 & 784,11 & 2,88 \\
\hline Média & 266.000 & 743,77 & 2,78 \\
\hline
\end{tabular}

A média da produção diária de biogás é de $743,77 \mathrm{~m}^{3}$. dia ${ }^{-1}$, para uma média de 266.000 animais abatidos, a uma temperatura de $30,3{ }^{\circ} \mathrm{C}$, ou seja, uma produção média de $2,78 \mathrm{~m}^{3}$. dia ${ }^{1}$ para cada animal abatido.

Potencial de produção de biogás na indústria de abate de frango no Brasil

O potencial de produção de biogás por estado brasileiro está representado na Tabela 4.

Tabela 4 - Potencial de produção de biogás no Brasil

\begin{tabular}{|c|c|c|}
\hline Estado & $\begin{array}{l}\text { Frangos abatidos } \\
\text { (dia) }\end{array}$ & $\begin{array}{c}\text { Biogás } \\
\left(\mathbf{m}^{3} \cdot \operatorname{dia}^{-1}\right)\end{array}$ \\
\hline Paraná & $3.976 .095,77$ & $11.053,54$ \\
\hline Santa Catarina & $2.431 .105,32$ & $6.758,47$ \\
\hline Rio Grande do Sul & $1.996 .603,55$ & $5.550,55$ \\
\hline São Paulo & $1.874 .287,97$ & $5.210,52$ \\
\hline Minas Gerais & $1.116 .456,82$ & $3.103,77$ \\
\hline Goiás & $882.973,76$ & $2.454,66$ \\
\hline Mato Grosso & $656.215,07$ & $1.824,27$ \\
\hline Mato Grosso do Sul & $387.575,57$ & $1.077,46$ \\
\hline Bahia & $221.168,41$ & 614,848 \\
\hline
\end{tabular}




\begin{tabular}{ccc}
\hline Pernambuco & $131.478,95$ & 365.511 \\
Pará & $114.488,90$ & 318.279 \\
Rio de Janeiro & $110.756,06$ & 307.901 \\
Espírito Santo & $72.090,98$ & 200.412 \\
Distrito Federal & $52.089,14$ & 159.611 \\
Paraíba & $57.414,36$ & 144.807 \\
Outros & $68.639,61$ & 190.818 \\
Total & $\mathbf{1 4 . 1 4 9 . 4 4 9}$ & $\mathbf{3 9 . 3 5 5 , 4 4}$ \\
\hline
\end{tabular}

O Paraná possui a maior capacidade até o momento de produzir biogás, cerca de $11.053,54 \mathrm{~m}^{3} \cdot \mathrm{dia}^{-1}$ e também o maior abate de frangos por dia.

Ao avaliar o potencial de produção de biogás por região, verifica-se que o Sul possui maior índice para produzir biogás, visto que é onde estão concentrados os maiores estados abatedoures de aves, Paraná, Santa Catarina e Rio Grande do Sul, que juntos possuem potencial de gerar 23.362,56 $\mathrm{m}^{3}$.dia ${ }^{-1}$ como representado na Tabela 5.

Tabela 5 - Potencial de produção de biogás por região brasileira

$\left.\begin{array}{ccc}\hline \text { Região } & \begin{array}{c}\text { Frangos abatidos } \\ (\mathbf{d i a})\end{array} & \begin{array}{c}\text { Biogás } \\ \left(\mathbf{m}^{\mathbf{3}} \mathbf{. d i a}\right.\end{array} \\ \hline \text { Sul } \mathbf{~}\end{array}\right)$

\section{Potencial de Produção de Energia a partir do Biogás}

Para converter o biogás em energia fez-se necessário o uso da relação $1 \mathrm{~m}^{3}$ de biogás que produz 1,47 kWh de energia utilizado na equação 4, possibilitando estimar a quantidade de energia que cada estado da federação e região poderia produzir através do biogás de agroindústrias. A tabela 6 demonstra a energia que pode ser produzida pelo biogás. 
Tabela 6 - Potencial de produção energética nos estados com maior índice de abate

\begin{tabular}{|c|c|}
\hline Estado & kWh \\
\hline Paraná & $16.248,70$ \\
\hline Santa Catarina & $9.934,95$ \\
\hline Rio Grande do Sul & $8.159,30$ \\
\hline São Paulo & $7.659,46$ \\
\hline Minas Gerais & $4.562,54$ \\
\hline Goiás & $3.608,35$ \\
\hline Mato Grosso & $2.681,67$ \\
\hline Mato Grosso do Sul & $1.583,89$ \\
\hline Bahia & 903,82 \\
\hline Pernambuco & 537,30 \\
\hline Pará & 467,90 \\
\hline Rio de Janeiro & 452,61 \\
\hline Espírito Santo & 294,60 \\
\hline Distrito Federal & 234,62 \\
\hline Paraíba & 212,90 \\
\hline Outros & 280,50 \\
\hline Total & $57.823,11$ \\
\hline
\end{tabular}

Os estados com maior abate de frangos e consequentemente com a maior produção de biogás, por sua vez serão os maiores produtores de energia. Assim sendo o Paraná enquadra-se neste perfil, com a maior capacidade de gerar biogás e produzir energia, seguido de Santa Catarina, Rio Grande do Sul e São Paulo.

A Região Sul segue com a maior produção de energia 34.342,97 kWh, seguida da região Sudeste com 12.969,23 kWh. Para a região Norte, observou-se a menor produção de energia, $538,41 \mathrm{kWh}$, e possui também o menor consumo de energia residencial de todas as regiões brasileiras. A soma de todas as regiões brasileiras geram $57.823,11 \mathrm{kWh}$ por dia, que convertidos gerariam aproximadamente $\mathbf{0 , 0 5 8} \mathrm{GWh}$ por dia, como mostrado na Tabela 7.

Tabela 7 - Potencial de energia produzida por região brasileira

\begin{tabular}{cc}
\hline Região & kWh \\
\hline Sul & $34.342,97$ \\
\hline
\end{tabular}

Revista Brasileira de Energias Renováveis, v. 3, p. 151-162, 2014 


\begin{tabular}{cc}
\hline Sudeste & $12.969,23$ \\
Nordeste & $1.863,93$ \\
Norte & 538,41 \\
Centro-Oeste & $8.108,53$ \\
Total & $\mathbf{5 7 . 8 2 3 , 1 1}$ \\
\hline
\end{tabular}

\section{Conclusão}

Neste trabalho foram levadas em consideração valores provenientes das características dos efluentes de agroindústria abatedoura de frangos. As variáveis como $\mathrm{pH}$, temperatura, $\mathrm{DBO}_{5,20}$, DQO e Sólidos Totais, demonstraram estar entre os padrões necessários para obter um biogás de qualidade entre os meses de janeiro a junho de 2012.

A concentração média de $\mathrm{H}_{2} \mathrm{~S}$ após passar por filtro de limalha de ferro foi de 843,88 ppm, com uma remoção média de 458,48 ppm, mantendo o $\mathrm{H}_{2} \mathrm{~S}$ abaixo dos 1000 ppm indicados para operar em motores geradores. A qualidade do biogás lhe conferiu um percentual de $73 \%$ de concentração em média de metano, o que corresponde a um poder calorífico de aproximadamente $7,6 \mathrm{kWh}$.

A média de produção de biogás entre os meses de janeiro a junho foi de $743,77 \mathrm{~m}^{3}$, com uma média de $2,78 \mathrm{~m}^{3}$ por animal abatido. O potencial de produção de biogás na indústria de abate de frangos brasileira apontou ser eficiente com um resultado de 39.335,44 $\mathrm{mil} \mathrm{m}^{3}$ por dia e um valor de conversão em energia de $57.823,11 \mathrm{mil} \mathrm{kWh}$ por dia, com um abate de frangos no total de 14.149.449 milhões por dia.

O estado com maior potencial para gerar biogás e energia foi o Paraná, a região com maior possibilidade de produção de biogás foi a região sul, pois os maiores estados abatedores de frangos estão nesta localização, a região com a menor possibilidade de gerar biogás e energia é o Norte.

O País ainda não possui a capacidade necessária para substituir a energia elétrica através do biogás, mas esta energia poderá ser utilizada concomitantemente a elétrica abastecendo pequenos centros urbanos ou ainda suprir ao menos a demanda das indústrias onde é produzida, desafogando o sistema elétrico brasileiro, que se encontra em crise. 


\section{Referências}

COSTA, D. F.; Geração de energia elétrica a partir de biogás de tratamento de esgoto. 2006. CORTEZ, L. A. B.; LORA, E. E. S.; GÓMEZ, E. O.; Biomassa para Energia. Campinas: UNICAMP, 2008.

IANNICELLI, L. A.; Reaproveitamento energético do biogás de uma indústria cervejeira. 2008, 83 F. Dissertação (Mestrado em Engenharia Mecânica) - Universidade de Taubaté. São Paulo, 2008.

INSTITUTO BRASILEIRO DE GEOGRAFIA E ESTATÍSTICA - IBGE. Indicadores do IBGE, Estatística da Produção Pecuária. $4^{\circ}$ Trimestre. 2012. Disponível em: $<$ http://www.ibge.gov.br/home/estatistica/indicadores/agropecuaria/producaoagropecuaria/aba te-leite-couro-ovos_201101_pub_completa.pdf> Acesso em: 05 nov 2013.

LUCAS JUNIOR, J.; Algumas considerações sobre o uso do estrume de suíno como substrato para três sistemas de biodigestores anaeróbios. Tese (Doutorado em Ciências Agrárias) Universidade Estadual Paulista: UNESP. Jaboticabal, 1994.

LINS, E.; et al., Avaliação da insalubridade causada pelo biogás de um aterro de resíduos urbanos. $23^{\circ}$ Congresso Brasileiro de Engenharia Sanitária e Ambiental, 2005.

NISHIMURA, R.; Análise de Balanço Energético de Sistema de Produção de Biogás em Granja de suínos: Implementação de Aplicativo Computacional. 2009, 97 F. dissertação (Mestrado em Engenharia Elétrica) - Universidade federal do Mato Grosso do Sul. Campo Grande, 2009.

OLIVEIRA, P. A. U.; et al., Uso dos resíduos de sistemas de crescimento e terminação de suínos para a produção de biogás. Congresso Brasileiro de Veterinários Especialistas em Suínos. Fortaleza, 2005, p. 512 - 513. 